\title{
PREPARASI PARTIKEL MAGNETIK DARI PASIR BESI PANTAI BATANG KAPAS SUMATERA BARAT MENGGUNAKAN METODE BALL MILLING
}

\author{
Tahayati Ichsan ${ }^{1, *}$, Salomo $^{2}$, Erwin $^{2}$, Usman Malik $^{2}$ \\ ${ }^{1}$ Mahasiswa Program SI Fisika \\ ${ }^{2}$ Dosen Bidang Instrmentasi dan Kemagnetan Jurusan Fisika \\ Fakultas Matematika dan Ilmu Pengetahuan Alam Universitas Riau \\ Kampus Bina Widya Pekanbaru, 28293, Indonesia \\ *E-mail korespondensi: ichsantahayati@gmail.com
}

\begin{abstract}
Preparation of micro magnetic particle and its magnetic propertis from iron sand beach of Batang Kapas west Sumatera using Ball Milling method has been done. Prior to the Ball Milling process, the samples were processed by iron sand separator (ISS) in order to separate between magnetic particles and non magnetic one. Next, the concentrates from ISS were crushed by Ball Milling method as a function of time namely 20, 40, and 60 hours. For separation between magnetic particles and non magnetic one, then NdFeB magnet was utilized. The results showed that the magnetic degree of the sample is about 0,5\%. Measurements of magnetic induction solenoids were carried out using a Magnetic Probe Pasco PS -2162 as a function of current (2, 4, 6, 8 and 10) $A$ and $a$ functions of distance (1, 2, 3, 4, and 5) $\mathrm{mm}$. Then the total magnetic induction of the solenoid (solenoid with sample core and concentrate) was measured as a function of an electric current for a fixed distance of 1 $\mathrm{mm}$. The calculation results showed that magnetic susceptibility and mass susceptibility increase with Ball Milling time from $(3376,400-7765,130) \times 10^{-3} \mathrm{~m}^{3} / \mathrm{K}$. This value is within the interval of $46-80000 \times 10^{-3} \mathrm{~m}^{3} /$ $\mathrm{K}$ which is the interval of Ilmenite mineral ( $\mathrm{FeTiO}_{3}$; Antiferromagnetik). The increase in magnetic susceptibility and mass susceptibility of samples processed by Ball Milling is thought to be due to the increasing number of magnetic particles in the sample.
\end{abstract}

Keywords: Iron sand, Magnetic Probe Pasco PS-2162, Ball Milling, Magnetic susceptibility, mass susceptibility.

\begin{abstract}
ABSTRAK
Telah dilakukan penelitian tentang preparasi partikel magnetik dari pasir besi pantai Batang Kapas Sumatera Barat dengan metode Ball Milling untuk mengetahui tingkat kemagnetan dan sifat magnetik dari pasir besi. Sebelum dilakukan proses Ball Milling, sampel terlebih dahulu dipisahkan mineral magnetiknya menggunakan Irond Sand Separator. Selanjutnya sampel dihancurkan menggunakan Ball Milling selama (20, 40, dan 60) jam kemudian dilakukan pemisahan kembali menggunakan magnet Niodinium Iron Boron (NdFeB). Tingkat kemagnetan yang diperoleh dari hasil perbandingan antara massa konsentrat hasil Ball Milling dan massa pasir besi adalah 0,5\%. Pengukuran induksi magnetik solenoida dilakukan menggunakan Probe Magnetic Pasco PS-2162 sebagai fungsi arus(2, 4, 6, 8 dan 10)A dan fungsi jarak (1, 2, 3, 4, dan 5)mm. Selanjutnya diukur nilai induksi magnetik total solenoid (solenoida dengan inti sampel dan konsentrat) sebagai fungsi arus listrik untuk jarak yang tetap yaitu $1 \mathrm{~mm}$. Hasil perhitungan menunjukkan bahwa nilai suseptibilitas magnetik dan suseptibilitas massa bertambah seiring dengan bertambahnya waktu Ball Milling dari (3376,400$7765,130) \times 10^{-8} \mathrm{~m}^{3} / K$. Nilai ini berada dalam interval $(46-80000) \times 10^{-8} \mathrm{~m}^{3} / K$ yang merupakan interval mineral Ilmenite ( $\mathrm{FeTiO}_{3}$; Antiferromagnetik). Meningkatnya nilai suseptibilitas magnetik dan suseptibilitas massa dari sampel yang telah diproses dengan Ball Milling diduga karena semakin besarnya jumlah partikel magnetik dalam sampel.
\end{abstract}

Kata kunci: Pasir besi, Magnetic Probe Pasco PS-2162, Ball Milling, suseptibilitas magnetik, suseptibilitas massa.

\section{PENDAHULUAN}

Indonesia termasuk salah satu negara yang memiliki sumber daya alam melimpah salah satunya yaitu bahan galian tambang. Beberapa bahan tambang yang banyak terdapat di Indonesia yaitu batu bara, emas, perak, nikel, tembaga, batu kapur, dan pasir besi [1]. Di daerah Sumatera Barat khusunya di pinggir 
Pantai Batang Kapas terdapat salah satu bahan tambang yang mudah ditemui dengan jumlah yang banyak yaitu pasir besi. Potensi pengembangan pertambangan pasir besi disepanjang pantai Sumatera Barat umumnya mempunyai kadar besi $2 \%$ sampai dengan $7 \%$ dan ketebalan bervariasi antara $2 \mathrm{~mm}$ sampai dengan $10 \mathrm{~cm}$ [2]. Pasir besi merupakan endapan pasir yang mengandung partikel bijih besi, dimana bijih besi tersebut dapat memiliki mineral-mineral magnetik seperti magnetit $\left(\mathrm{Fe}_{3} \mathrm{O}_{4}\right)$, hematit $\left(\alpha-\mathrm{Fe}_{2} \mathrm{O}_{3}\right)$ dan maghemit $\left(\gamma-\mathrm{Fe}_{2} \mathrm{O}_{3}\right)$. Magnetit memiliki fasa kubus, sedangkan maghemit dan hematit memiliki fasa kubus dan heksagonal namun keduanya memiliki komposisi kimia sama. Berbagai aplikasi tentang pasir besi seperti pada bidang industri otomotif, elektronika, dan peralatan rumah tangga telah banyak dikembangkan [3].

Para peneliti melakukan identifikasi dan karakterisasi untuk mengetahui sifat magnetik pasir besi dengan berbagai cara salah satunya yaitu dengan menggunakan metode Ball Milling. Metode Ball Milling merupakan proses penggilingan atau penghancuran material atau bahan asal pasir besi sehingga diperoleh ukuran yang sangat halus mencapai ukuran mikrometer ( $\mathrm{m}$ ) hingga nanomater $(\mathrm{nm})$. Penggilingan ini bertujuan untuk memperoleh bulir-bulir bahan magnet yang memiliki domain magnetik tunggal (single domain) sebelum diolah lebih lanjut menjadi barang komoditi [4].

Penelitian terdahulu [5] telah berhasil mengkaji sifat magnetik dan struktur partikel oksida dari endapan pasir besi yang berada di Pantai Kata Pariaman Sumatera barat dengan menggunakan metode Ball Milling. Selanjutnya [6] telah melakukan sintesis nanopartikel magnetik khususnya mineral magnetit dengan Ball Milling yang berenergi tinggi. Dari penelitian tersebut dikatakan bahwa waktu penggilingan merupakan parameter utama untuk mendapatkan magnetit murni.

Dengan luasnya aplikasi dari partikel magnetik pasir besi maka dilakukan preparasi partikel magnetik dari pasir besi Pantai Batang Kapas Sumatera Barat dengan metode Ball Milling, untuk mengetahui sifat magnetik yang terdiri dari nilai induksi magnetik yang akan diukur menggunakan sensor Magnetic Probe Pasco PS-2162, kemudian nilai suseptibilitas magnetik dan suseptibilitas massa serta tingkat kemagnetan dari pasir besi Pantai Batang Kapas Sumatera Barat sehingga dapat dimanfaatkan dan mendapat nilai tambah dibidang ekonomi.

\section{METODE PENELITIAN}

Metode yang digunakan dalam penelitian ini adalah metode eksperimen untuk menentukan sifat magnetik khususnya nilai induksi magnetik, suseptibilitas magnetik, suseptibilitas massa dan tingkat kemagnetan.

\section{Prosedur Pengambilan Sampel}

Sampel yang digunakan dalam penelitian ini diambil dari 5 lokasi yaitu lokasi A, B, C, $\mathrm{D}$, dan $\mathrm{E}$ dipinggiran Pantai Batang Kapas Sumatera Barat dengan massa masing-masing lokasi adalah $6 \mathrm{~kg}$, tiap lokasi terdiri dari 4 titik. Jarak antara masing-masing lokasi adalah 5 meter. Cara pengambilan sampel dilakukan dengan metode zigzag untuk setiap titik dan juga antara masing-masing lokasi.Sampel yang sudah diambil kemudian dibawa ke Laboratorium Instrumentasi dan Magnetik Jurusan Fisika Universitas Riau menggunakan wadah.

\section{Prosedur Pemisahan Partikel Magnetik dengan menggunakan Iron Sand Separator.}

Pasir besi yang telah diambil dari 5 lokasi terlebih dahulu dikeringkan dan ditimbang, kemudian dilakukan proses pemisahan antara partikel magnetik dari pasir besi dengan menggunakan Iron Sand Separator. Proses pemisahan dilakukan sebanyak 3 kali pengulangan untuk mendapatkan konsentrat yang bersih. 


\section{Pengukuran Nilai Induksi Magnetik}

Sebelum dilakukan pengukuran terhadap nilai induksi magnetik maka langkah pertama adalah proses pembuatan sebuah solenoid dengan panjang $10 \mathrm{~cm}$, diameter $3 \mathrm{~cm}$ dan jumlah lilitan adalah sebanyak 2000 lilitan kemudian dihubungkan dengan arus listrik. Pengukuran nilai induksi magnetik dapat dilakukan dengan menggunakan sensor Magnetic Probe Pasco PS-2162 sebagai fungsi arus $(2,4,6,8$ dan 10) A dan jarak (1, 2, 3, 4 dan 5) $\mathrm{mm}$. Pertama dilakukan pengukuran nilai induksi magnetik solenoid tanpa inti $\left(\mathrm{B}_{0}\right)$ sebagai fungsi arus dan fungsi jarak, selanjutnya diukur nilai induksi magnetik solenoid dengan inti pasir besi sebelum proses pemisahan dan nilai induksi magnetik solenoid dengan inti konsentrat $\left(\mathrm{B}_{\mathrm{T}}\right)$ setelah proses pemisahan dengan mengunakan Iron Sand Separator sebagai fungsi arus.

\section{Proses Ball Milling}

Sampel yang telah melewati proses Iron Sand Separator yang menghasilkan konsentrat dengan nilai induksi magnetik total paling tinggi kemudian dihancurkan lagi menggunakan Ball Milling untuk mendapatkan kosentrat yang lebih halus. Konsentrat tersebut dibagi menjadi 3 bagian sama rata sebelum proses penghancuran menggunakan Ball Milling dengan waktu yang bervariasi yaitu (20, 40, dan 60) jam. Setelah proses Ball Milling kemudian konsentrat di dipisahkan kembali menggunakan magnet Niodinium Iron Boron (NdFeB). Masing-masing konsentrat dihitung induksi magnetik totalnya $B_{T}$ sebagai fungsi arus (2, 4, 6, 8, dan 10) A dengan jarak tetap $1 \mathrm{~mm}$ dari ujung tengah solenoid.

\section{Menentukan suseptibilitas magnetik dan suseptibilitas massa}

Nilai suseptibilitas magnetik dapat ditentukan setelah diperoleh nilai induksi magnetik.Sampel dan konsentrat yang telah diukur besar induksi magnetiknya selanjutnya akan diukur volume dengan menggunakan gelas ukur dan massa masing-masing. Hasil pengukuran volume dan massa digunakan untuk mengetahui rapat massa yang merupakan salah parameter untuk menentukan suseptibilitas massa.

\section{Menentukan Tingkat Kemagnetan (Magnetic Degree)}

Tingkat kemagnetan dari pasir besi Pantai Batang Kapas Sumatera Barat dapat ditentukan dengan membandingkan massa total konsentrat hasil Ball Milling dengan massa total pasir besi dari satu lokasi.

\section{HASIL DAN PEMBAHASAN}

\section{Pengukuran Induksi Magnetik}

Pertama kali dilakukan pengukuran nilai induksi magnetik solenoid tanpa inti sebagai fungsi arus dan fungsi jarak diperoleh data seperti yang terlihat pada Gambar 1 dan Gambar 2.

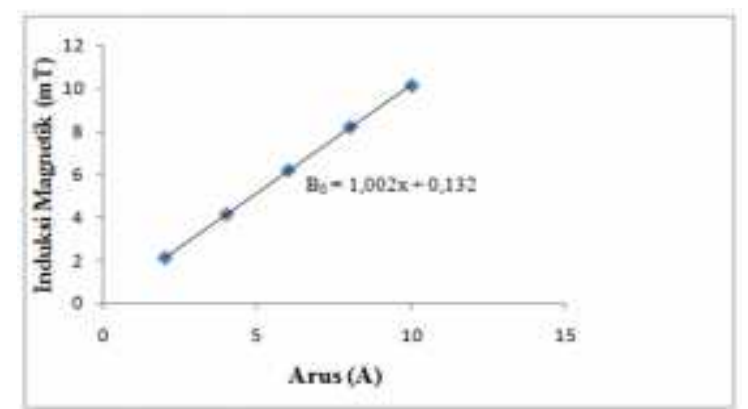

Gambar 1. Grafik hubungan antara induksi magnetik $\left(\mathrm{B}_{0}\right)$ dengan fungsi arus (I) pada jarak tetap $(1 \mathrm{~mm})$ dari ujung tengah solenoid.

Berdasarkan Gambar 1. Dapat dilihat bahwa nilai induksi magnetik solenoid berbanding lurus dengan nilai arus yang diberikan. Berdasarkan Gambar 2 Dapat dilihat bahwa nilai induksi magnetik solenoid berbanding terbalik dengan nilai jarak yang diberikan semakin besar jarak yang diberikan maka nilai induksi magnetik solenoid semakin kecil. 


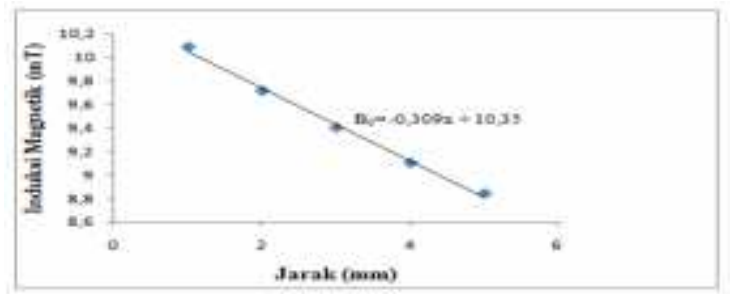

Gambar 2. Grafik hubungan antara induksi magnetik $\left(\mathrm{B}_{0}\right) \quad$ dengan jarak horizontal pada arus tetap (10 A).

Hal ini disebabkan karena Magnetic Probe Pasco PS-2162 semakin menjauhi kutub magnet yang terletak di ujung tengah solenoid. Perbandingan nilai induksi magnetik tanpa inti dengan nilai induksi magnetik dengan inti sampel, konsentrat hasil Iron Sand Separator, dan konsentrat hasil Ball Milling ditunjukkan pada Gambar 3.

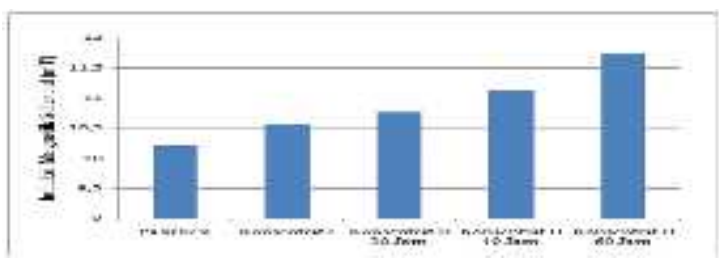

Gambar 3. Grafik perbandingan nilai induksi magnetik solenoid tanpa inti dan dengan inti pada arus $10 \mathrm{~A}$.

Nilai induksi magnetik total dari konsentrat I (setelah diproses dengan Iron Sand Separator) memiliki nilai induksi magnetik total lebih tinggi dari induksi magnetik total sampel sebelum pemisahan hal ini disebabkan karena mineral magnetik dengan non magnetik telah dipisahkan menggunakan Iron Sand Separator, namun masih terdapat bongkahan-bongkahan seperti titanium, magnesium, kalsium, dan silikon yang terbawa pada waktu proses pemisahan. Nilai induksi magnetik total tertinggi adalah dari konsentrat II yang berasal dari konsentrat I setelah dihancurkan dengan Ball Milling selama 20, 40, dan 60 jam kemudian dipisahkan kembali dengan menggunakan magnet Niodinium Iron Boron ( $\mathrm{NdFeB}$ ). Konsentrat yang diproses dengan Ball Milling selama 60 jam memiliki nilai induksi magnetik total paling tinggi yaitu sebesar $11,752 \mathrm{mT}$.
Besarnya nilai induksi magnetik total dari konsentrat II berbanding lurus dengan lamanya waktu Ball Milling. Semakin lama waktu Ball Milling maka nilai induksi magnetik total semakin besar hal ini disebabkan karena semakin lama diproses dengan Ball Milling maka konsentrat I yang masih mengandung bongkahan-bongkahan akan semakin hancur dan pada proses pemisahan dengan magnet Niodinium Iron Boron (NdFeB) yang menempel hanya mineral magnetiknya.

\section{Suseptibilitas Magnetik}

Nilai suseptibilitas magnetik diperoleh setelah pengukuran nilai induksi magnetik solenoid tanpa inti dan nilai induksi magnetik total solenoid dengan inti. Data hasil pengukuran nilai suseptibilitas magnetik dari konsentrat hasil Ball Milling dapat dilihat pada Tabel 1 dan grafik hubungan antara nilai suseptibilitas magnetik dengan lamanya waktu Ball Milling dapat dilihat pada Gambar 4.

Tabel 1. Nilai suseptibilitas magnetik sampel dan konsentrat II (setelah diproses dengan Ball Milling dan dipisahkan dengan Magnet Niodinium Iron Boron (NdFeB)) pada $10 \mathrm{~A}$.

\begin{tabular}{|c|c|c|c|}
\hline $\begin{array}{c}\text { Waktu Ball } \\
\text { Milling (jam) }\end{array}$ & $\mathrm{B}_{0}(\mathrm{mT})$ & $\mathrm{B}_{\mathrm{T}}(\mathrm{mT})$ & $\chi_{\mathrm{m}}\left(\times 10^{-5}\right)$ \\
\hline 0 & 10,106 & 10,215 & 1078,567 \\
\hline 20 & 10,106 & 10,762 & 6491,200 \\
\hline 40 & 10,106 & 11,140 & 10231,500 \\
\hline 60 & 10,106 & 11,752 & 16287,400 \\
\hline
\end{tabular}

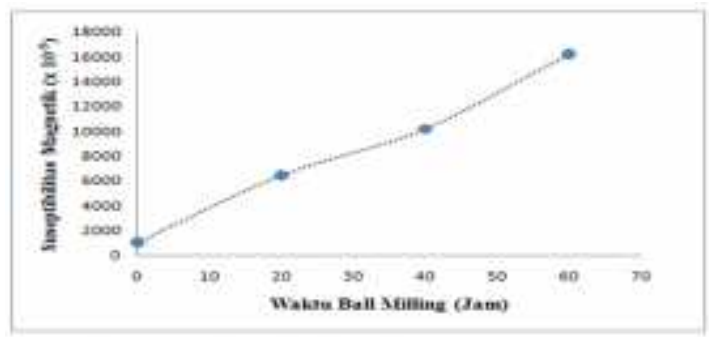

Gambar 4. Grafik hubungan nilai suseptibilitas magnetik dengan waktu Ball Milling pada arus $10 \mathrm{~A}$. 
Tabel 1 menunjukkan nilai suseptibilitas magnetik dari sampel sebelum diproses dengan Ball Milling dan nilai suseptibilitas magnetik dari konsentrat yang telah diproses dengan Ball Milling selama 20, 40, dan 60 jam pada arus $10 \mathrm{~A}$. Dapat dilihat bahwa antara nilai suseptibilitas magnetik dengan lamanya waktu Ball Milling berbanding lurus. Nilai suseptibilitas magnetik terendah berasal dari sampel sebelum diproses dengan Ball Milling dengan nilai sebesar $1078,567 \times 10^{-5}$, dan nilai suseptibilitas magnetik tertinggi berasal dari konsentrat yang telah diproses dengan Ball Milling selama 60 jam yaitu sebesar $16287,400 \times 10^{-5}$. Konsentrat II (setelah diproses dengan Ball Milling) memiliki nilai suseptibilitas magnetik paling tinggi jika dibandingkan dengan seluruh sampel dan konsentrat karena memiliki kosentrasi mineral magnetik yang lebih tinggi. Secara keseluruhan nilai suseptibilitas magnetik konsentrat II berada dalam interval nilai mineral Ilmenite $\left(\mathrm{FeTiO}_{3}\right.$; Anti ferromagnetik) dengan rentang nilai $(200-380000) \times 10^{-5}$ [7].

\section{Suseptibilitas Massa}

Nilai suseptibilitas massa dihitung setelah diketahui nilai induksi magnetik, nilai suseptibilitas magnetik, dan rapat massa dari suatu sampel.

Berdasarkan Gambar 5 dapat dijelaskan bahwa nilai suseptibilitas massa terendah berasal dari sampel yang belum diproses dengan Ball Milling dengan nilai 710,519 $\times$ $10^{-\forall} \mathrm{m}^{3} / K$, dan nilai suseptibilitas massa tertinggi berasal dari konsentrat yang telah diproses dengan Ball Milling selama 60 jam dengan nilai $7765,130 \times 10^{-8} \mathrm{~m}^{3} / K$. Nilai suseptibilitas yang diperoleh berdasarkan proses Ball Milling sebagai fungsi waktu menunjukkan bahwa nilai suseptibilitas massa meningkat seiring dengan bertambahnya waktu Ball Milling. Nilai ini berada dalam interval $(46-80000) \times 10^{-8} \mathrm{~m}^{3} / K \quad$ berarti bahwa partikel magnetik yang terdapat di Pantai Batang Kapas Sumatera Barat adalah mineral ilmenite $\left(\mathrm{FeTiO}_{3}\right.$;Antiferromagnetik) [7].

Tabel 2. Nilai suseptibilitas massa sampel dan konsentrat II (setelah diproses dengan Ball Milling dan pemisahan dengan magnet Niodinium Iron Boron (NdFeB)) pada $10 \mathrm{~A}$.

\begin{tabular}{|c|c|c|}
\hline $\begin{array}{c}\text { Waktu Ball } \\
\text { Milling (Jam) }\end{array}$ & $\begin{array}{c}\rho \\
\left(\mathrm{kg} \mathrm{m}^{5}\right)\end{array}$ & $\begin{array}{c}\gamma_{\text {mass }} \\
\left(\times 10^{-8} \mathrm{~m}^{3} / \mathrm{kg}\right)\end{array}$ \\
\hline 20 & 1518,000 & 710,519 \\
\hline 20 & 1922,500 & 3376,400 \\
\hline 40 & 1785,700 & 5729,710 \\
\hline 60 & 2097,500 & 7765,130 \\
\hline
\end{tabular}

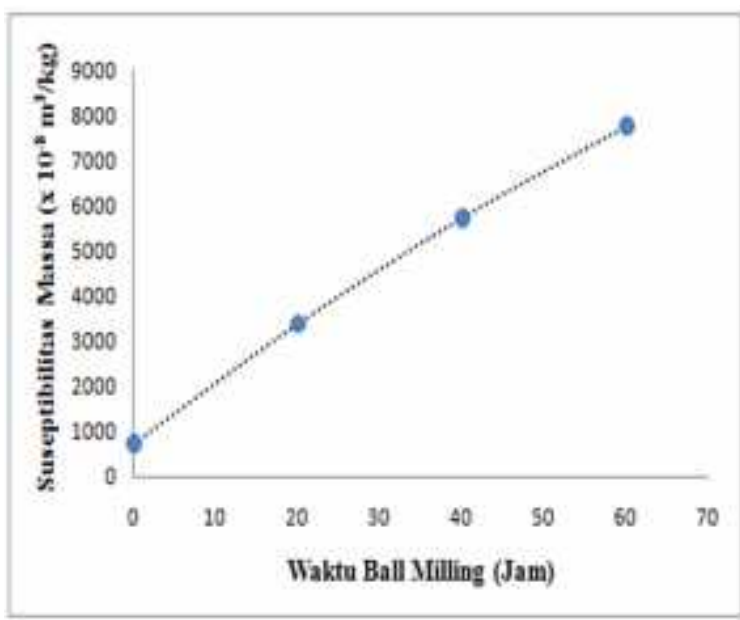

Gambar 5. Grafik nilai suseptibilitas massa dengan waktu Ball Milling pada arus $10 \mathrm{~A}$.

\section{Tingkat Kemagnetan (Magnetic Degree)}

Massa total konsentrat hasil Ball Milling diperoleh sebanyak $28,58 \times 10^{-3} \mathrm{~K}$ kemudian dibandingkan dengan massa pasir besi $6 \quad \mathrm{~kg}$ sehinggga diperoleh tingkat kemagnetan pasir besi Pantai Batang Kapas sebesar $0,5 \%$. Tingkat kemagnetan ini tergolong rendah hal ini disebabkan karena sedikitnya kandungan mineral magnetik yang terdapat pada Pantai Batang Kapas Sumatera Barat, ditandai dengan warna pasir besi yang tidak begitu hitam. 


\section{KESIMPULAN}

Nilai induksi magnetik total tertinggi dimiliki oleh sampel yang telah diproses dengan Ball Milling selama 60 jam dan nilai induksi magnetik total terendah dimiliki oleh sampel sebelum proses pemisahan. Nilai suseptibilitas magnetik pasir besi Pantai Batang Kapas Sumatera Barat yang telah diproses dengan Ball Milling berada dalam interval (200$380000) \times 10^{-5}$ yang merupakan interval mineral Ilmenite $\left(\mathrm{FeTiO}_{3}\right.$; Antiferromagnetik). Nilai suseptibilitas massa pasir besi Pantai Batang Kapas Sumatera Barat yang telah diproses dengan Ball Milling berada dalam interval $(46-80000) \times 10^{-\sharp} \mathrm{m}^{3} / k$ yang merupakan interval mineral Ilmenite $\left(\mathrm{FeTiO}_{3}\right.$; Antiferromagnetik). Konsentrat yang telah diproses dengan Ball Milling selama 60 jam memiliki nilai induksi magnetik total dan nilai suseptibilitas paling tinggi, sedangkan konsentrat yang telah diproses dengan Ball Milling selama 20 jam memiliki nilai induksi magnetik total dan nilai suseptibilitas paling rendah artinya lamanya waktu sangat berpengaruh pada sifat magnetik pasir besi. Tingkat kemagnetan dari pasir besi Pantai Batang Kapas Sumatera Barat tergolong rendah yaitu sebesar $0,5 \%$.

\section{DAFTAR PUSTAKA}

1. Palkrisman \& Budiman, A. (2014). Pemetaan Persentase Kandungan dan Nilai Suseptibilitas Mineral Magnetik Pasir Besi Pantai Sunur Kabupaten Padang Pariaman Sumatra Barat. Jurnal Fisika Unand, 3(4).
2. Sektor Pertambangan Sumbar. (2014). http://www.sumbarprov.go.id/details/new s/2700 Diakses pada 25 Maret 2018

3. Yulianto, A., Bijaksana, S., \& Loeksmato, W. (2002). Karakterisasi Magnetik dari Pasir Besi Cilacap. Jurnal Fisika Himpunan Fisika Indonesia, A5(0527).

4. Ihsan, Y. (2006). Rancangan Bangun dan Karakterisasi Ball Milling untuk Proses Penghancuran Serbuk BahanMagnetik. Semarang : Universitas Semarang.

5. Marihot, D. (2017). Sintesis dan Karakterisasi Sifat Magnetik dan Struktur Partikel Oksida Besi Endapan Pasir Besi Pantai Kata Pariaman Sumatera Barat. Tesis. Universitas Riau: Pekanbaru.

6. Carvalho de, J. F, Medeiros de S. N, Morales, M. A, Dantas, A. L, \& Carrico, A. S. (2013). Synthesis of Magnetite Nanoparticles by High Energy Ball Milling. Applied Surface Science, 275, 8487.

7. Hunt, C. P., Moskowitz, B. M., \& Banerjee, S. K., (1995). Magnetic Properties of Rokcs and Minerals. 